\title{
DO PRINCÍPIO DIALÓGICO E SUA CORRELAÇÃO COM AS MATERIALIDADES DISCURSIVAS VERBO-VISUAIS EM PLATAFORMAS ONLINE.
}

\section{THE DIALOGICAL PRINCIPLE AND ITS CORRELATION WITH THE VERBAL- VISUAL DISCURSIVE MATERIALITIES IN ONLINE PLATFORMS.}

\author{
Aguinaldo Gomes de Souza ${ }^{64}$
}

\begin{abstract}
RESUMO: No presente estudo temos por objetivo colocar em diálogo os caminhos que Martin Buber e Mikhail Bakhtin sinalizaram sobre o conceito de diálogo e dialogismo e verificar como esses conceitos podem ser aplicados aos elementos verbo-visuais presentes em software. O conceito de dialogismo aqui explorado pode ser percebido particularmente em Buber (1878-1965) nos escritos "Eu-Tu" (Ich und Du, 1974) e "Do diálogo e do dialógico" (Das Dialosgische Prinzip, 1982). Em Bakhtin no todo de sua obra; particularmente e de forma mais percebida em "Para uma filosofia do ato responsável (1919-1921)"; em "Para uma reelaboração do livro sobre Dostoiévski" encontrado em "Problemas da poética de Dostoiévski (2002)" e no manuscrito "Das notas feitas" e "O problema do texto" ambos encontrados em "Estética da criação verbal" e possivelmente escritos em 1959/1960. Os achados apontam para uma hibridização de elementos verbo-visuais presentes em plataformas digitais, o que implica dizer que as relações que se estabelecem nesses ambientes são cada vez mais sustentadas por signos verbais e verbo-visuais.
\end{abstract}

PALAVRAS-CHAVE: Buber. Bakhtin. Verbo-visuais.

\begin{abstract}
In the present study we aim to put into dialogue the paths that Martin Buber and Mikhail Bakhtin signaled about the concept of dialogue and dialogism and to verify how these concepts can be applied to the verbal-visual elements present in software interfaces. The concept of dialogism explored here can be seen particularly in Buber (1878-1965) in the writings "I-Tu" (Ich und Du, 1974) and "Dialogue and Dialogic" (Das Dialosgische Prinzip, 1982). And in Bakhtin, in the whole of his work, particularly and most noticeably in "Towards a philosophy of the responsible act (1919-1921)", in "Towards a reworking of the book on Dostoevsky" found in "Problems of Dostoevsky's poetics 2002) and in the manuscript "Of the notes made" and "The problem of the text" both found in "Aesthetics of verbal creation" and possibly written in 1959/1960. The findings point to a hybridization of verbal-visual elements present in digital platforms, which implies that the relations established in these environments are increasingly supported by signs.
\end{abstract}

KEYWORDS: Buber. Bakhtin. Verbal-Visual.

\section{Introdução}

É fato que os biógrafos de Mikhail Bakhtin já apontavam que desde a infância ele e o irmão mais velho, Nicolau, já possuíam uma formação precoce em filosofia. Dentre as influências filosóficas de Bakhtin, Clark e Holquist $\left(1998^{65}\right)$ destacam a presença de Buber (1878-1965). Os biógrafos afirmam que o jovem Bakhtin, assim que se mudou para Odessa, por intermédio de um tutor, teve contato com as ideias desse filósofo e a posteriori com as de Kierkegaard ${ }^{66}$, o filósofo do cristianismo. Interessante notar que a filosofia de Kierkengaard vai influenciar tanto Bakhtin quanto Buber (op. cit.) sendo consenso considerar Kierkengaard

\footnotetext{
${ }^{64}$ Doutorando em Linguística pela Universidade Federal de Pernambuco. Web site: www.aguinaldogomes.com

${ }^{65}$ Na página 27 "This tutor introduced Bakhtin to the work Martin Buber. Soon after arriving in Odessa, Bakhtin also read Kierkegaard, to whom he was so attracted that he tried to learn Danish in order".

${ }^{66}$ O pensamento desenvolvido pelo filósofo gira ao redor da temática do "ser existente"; nesse sentido, o indivíduo e a existência são entidades puramente subjetivas. Kierkegaard é considerado o fundador do existencialismo, conforme mostra Strathern (1999). A preocupação do filósofo era escrever sobre a vida e sobre como vivemos e escolhemos viver.
} 
como o filósofo pai do existencialismo. Mais comum ainda é encontrar traços de semelhanças entre a questão existencial, entre o existencialismo e o pensamento de Bakhtin ${ }^{67}$.

É possível notar isto quando se considera que a filosofia de Bakhtin é de base fenomenológica na qual o sentido ontológico do ser se constitui na relação com o outro. Temos então uma filosofia do diálogo em que o outro (a outridade) constitui fator importante. Para ele, a vida é um diálogo contínuo que ocorre a cada momento da existência. Essa natureza dialógica é constitutiva da vida, como assevera Bakhtin e Buber, respectivamente: Natureza dialógica da consciência, natureza dialógica da própria vida humana. A
única forma adequada de expressão verbal da autêntica vida do homem é o diálogo
inconcluso. A vida é dialógica por natureza. Viver significa participar do diálogo:
interrogar, ouvir, responder, concordar, etc. Nesse diálogo o homem participa inteiro
e com toda a vida: com os olhos, os lábios, as mãos, a alma, o espírito, todo o corpo,
os atos. Aplica-se totalmente na palavra, e essa palavra entra no tecido dialógico da
vida humana, no simpósio universal (BAKHTIN, 2006, p. 348)

Os domínios da vida dialógica e da vida monológica não coincidem com os do diálogo e do monólogo, mesmo se nestes incluirmos suas formas sem som e sem gesto. Não existem somente grandes esferas da vida dialógica que na sua aparência não são diálogo, mas existe também o diálogo que não é diálogo enquanto forma de vida, isto é, que tem a aparência de um diálogo, mas não a sua essência. Aliás, parece, às vezes, que esta última espécie é a única que ainda existe (p.53). A vida dialógica não é uma vida em que se tem muito a ver com os homens, mas é uma vida em que, quando se tem a ver com os homens, faz-se isto de uma forma verdadeira (p.54). O diálogo entre meros indivíduos é apenas um esboço; é somente entre pessoas que ele se realiza. Mas por que meios poderia um transformar-se, tão essencialmente, de indivíduo em pessoa, senão pelas experiências austeras e ternas do diálogo, que lhe ensinam o conteúdo ilimitado limite? (BUBER, 1982, p. 53-54)

Martin Buber (1982) pode ser considerado o mais expressivo dentre aqueles que se dedicaram à filosofia do diálogo e do Dialógico. Para Buber (op. cit.), o diálogo pertence e é constitutivo do modo ontológico de sermos, o dialógico nos abre as possiblidades de encontro com o outro. Bakhtin (2003) vai considerar, conforme Morson; Emerson (2008, p.78), que "o diálogo da vida requer um método dialógico e uma concepção dialógica da verdade para representá-la". Para formular o conceito de dialogia Buber (2001) invoca a ideia do modo EuTu. É no Eu-Tu que acontecem as relações. O Eu-Tu é o alternativo ao Eu-Isso, da coisificação, o Eu-Tu é uma palavra-princípio que se funda na ação. Para Buber (2001, p.03) "uma palavra-princípio não é um vocábulo, mas sim um par de vocábulos que funda uma existência".

O modo fenomenológico de Buber (op. cit.) é o modo da ação, a vivência deste modo em um dado instante da vida e tem a característica de ser dialógica. O logos desse modo fenomenológico funda-se no sentido, logos é sentido. Esse modo é o modo ser do logos, é o modo ontológico do ser que vivencia sentidos.

Os signos da palavra dirigida a alguém não são algo de extraordinário, algo que as destaca da ordem comum das coisas; são justamente o que se passa de tempo em tempo justamente o que se passa de qualquer maneira, nada lhes é acrescentado pela palavra dirigida. As ondas do éter vibram sempre, mas, na maioria das vezes estamos com os nossos receptores desligados. Aquilo que me acontece é palavra que me é dirigida. Enquanto coisas que me acontecem, os eventos do mundo são palavras que me são dirigidas. Somente quando eu os esterilizo, eliminando neles o

\footnotetext{
${ }^{67}$ Embora alguns estudiosos de sua vida o considerem como um filósofo assistemático, como é o caso de Clark e Holquist (1998)
} 
germe da palavra dirigida, é que posso compreender aquilo que me acontece como uma parte dos eventos do mundo que não me dizem respeito. O sistema interligado esterilizado, no qual tudo isto só precisaria ser inserido, é a obra titânica da humanidade. É a linguagem, ela também, foi colocada ao seu serviço. (BUBER, (1982, p. 43-44)

Assim podemos então dizer que, para Buber (1982; 2001), o homem existe no encontro dialógico. Ainda assim, esse homem entendido como um ser-ao-mundo não pode de nenhuma maneira ser pensado como um ser que se finda em si, ele é antes abertura para o diálogo. E aqui voltamos ao mecanismo essencial do pensamento dialógico de Buber (1982): o ser só se instaura na existência pela palavra e é pela palavra princípio Eu-Tu que a relação com o outro se torna uma abertura ao outro, um inter-humano que se funda na aproximação, no contato, na liberdade do estar junto. Desse modo o Eu-tu (a palavra da relação) funda o nó essencial do inter-humano. Buber (1982, p. 138) vai dizer que essa "esfera do inter-humano é aquela do face a face, do um-ao-outro; é o seu desdobramento que chamamos de dialógico".

\section{Da palavra para a palavra}

Quando Bakhtin começa a teorizar sobre a palavra, ele o faz, conforme Morson; Emerson (2008, p.101), não meramente como "um dentre os vários tipos de material da atividade literária, mas como, em primeiro lugar, o sentimento de que o significado está sendo gerado ativamente, então ele pode refundir a ideia da composição, a partir de sua estrutura vagamente formalista, em uma ideia dialógica".

Essa concepção de palavra vai, ao longo do tempo, ser retomada por Bakhtin e é o que vai separá-lo de Buber (op. cit.) no tocante a aplicabilidade do conceito de dialogismo. Nesse sentido, é útil retomar Bakhtin (2003) quando escreveu em "O problema do texto na linguística, na Filologia e nas Ciências Humanas", publicado no Brasil em "Estética da criação Verbal", que a língua e a palavra são quase tudo na vida humana. Ainda sobre o papel da palavra, na dialogia, Morson; Emerson (2008) observa que em "O problema do conteúdo", Bakhtin (1998) tenta estabelecer uma metodologia que pudesse dar conta e explicasse como as palavras podem transmitir juízos éticos (chamado por ele de "conteúdo") em forma de estética. Tal intento só vai gerar frutos quando, no final da década, ele desenvolve o modelo da palavra dialógica.

A palavra pode ser revestida de uma técnica e restaurada numa tipologia sem nenhum perigo de "mecanização", porque agora a tipologia diz respeito não aos dispositivos, mas às vozes. As vozes já têm "tom" e "conteúdo". Tendo recuperado a composição verbal para o saber literário não-formalista (isto é, dialógico). MORSON; EMERSON (2008, p.101)

Ora, diria Buber (1982, p.44) em "Do diálogo e do dialógico", que "aquilo que me acontece é palavra que me é dirigida. Enquanto coisas que me acontecem, os eventos do mundo são palavras que me são dirigidas". Esse modo fenomenológico da palavra vai ganhar contornos quando Bakhtin (1998) começa a empregar as categorias de 'autores, vozes e entonação' dentro da sua filosofia. Em Buber (1982) esse phainesthai da palavra vai ser retomado quando ele começa a esboçar o conceito basilar do dialogismo, a relação Eu-Tu. Nesse sentido, não seria estranho afirmar que tanto para Buber(1982) quanto para Bakhtin(1998) o dialogismo são as relações de sentidos que ocorrem dentro das palavras, dentro dos enunciados. O sentido, para Buber (op. cit.), é fenômeno-lógico, e é o modo de ser da ação, ele é uma contínua consciência de possibilidade. O ser é dialógico, pois é um ser de sentido que se constitui em uma dualidade Eu-Tu. 
O modo de ser da ação não se constitui em uma relação Eu-Isso, sujeito-objeto, mas acontece ao contato de duas consciências. Essa dualidade Eu-Tu é uma relação de sentido, na medida em que Eu-Tu são possibilidades que estão intrinsicamente ligadas e gera uma esfera de produção de sentidos, o que Buber chama de 'o entre'. Esse processo que vincula o sujeito na vivência da existência e da ação e que articula o Eu-Tu, chama-se 'dia'. Por ser o 'entre' uma esfera de produção de sentido, uma esfera de desdobramento de possiblidades chama-se de 'inter-sentidos', como pontuou Da Fonseca (2012). Essa esfera entre o Eu e o Tu é o dialógico. Dialógico é a esfera de compartilhamento de sentido, e é uma característica da ação fenomenológica do ser. $O$ dialógico é uma característica ontológica ${ }^{68}$ da vivência fenomenológica ${ }^{69}$.

Um traço comum em Buber e Bakhtin diz respeito, como mostra Nuto (2008), à valorização do que é concreto, singular e irrepetível na vida humana em oposição às generalizações abstratas. Tal perspectiva coloca Bakhtin(1998) e Buber(1982) entre os filósofos que enquadram o mundo como uma possibilidade de realização dialogal. Nesse sentido, é importante frisar que o pensamento de Buber (1982) abarca áreas diferentes do ser, como a educação, a sociologia, a política e a antropologia filosófica. Parece-nos importante notar outro traço constitutivo do fazer filosófico de ambos os filósofos: o modo como eles chegam às categorias filosóficas que são fundantes em suas obras. Tanto Buber (op. cit.) quanto Bakhtin(op. cit.) chegam até a ideia de alteridade, de diálogo e dialogismo não por vias do pensamento dedutivo mas por meio das relações, do vivencial, do concreto e existencial, do ser.

O conceito de dialogia em Buber (1982) vai perpassar outros campos da atividade humana, por exemplo, no mundo das artes. Nesse sentido, no livro "Do diálogo e do dialógico" Buber (1982, p.60) pondera que

\begin{abstract}
desde sua origem, toda arte é essencialmente dialógica: toda música é dirigida a um ouvido que não é o do próprio músico, toda escultura, a um olho que não é o do escultor; também a arquitetura é dirigida às pessoas que medem a obra. Todas elas dizem, àquele que as recebe, algo que só pode ser dito nesta linguagem única (não um 'sentimento', mas um segredo percebido).
\end{abstract}

Ainda em "Do diálogo e do Dialógico" Buber (1982) vai ponderar que o dialogismo não se restringe ao mundo das artes como tal, mas é antes parte constitutiva de toda e qualquer forma de pensamento, independente da presença física de um interlocutor.

Como podemos, observar as concepções utilizadas por Buber (op. cit.), em sua filosofia, são caras ao pensamento de Mikhail Bakhtin(2003) e é comum encontrarmos pontos de contato não só quando o teórico russo trata da questão do dialógico, mas também quando ele envereda por outros caminhos como, por exemplo, o conceito de ética, de responsabilidade ${ }^{70}$, etc. Elas se deixam vislumbrar quando, por exemplo, Bakhtin (2003) vai tratar da questão de outrem que é força motriz na constituição do "eu". Vejamos, por exemplo, "Estética da criação verbal", na qual Bakhtin (2003, p. 57) vai enunciar que

a forma concreta da vivência real do homem emana de uma correlação entre as categorias representativas do eu e do outro; as formas do eu através das quais sou o único a vivenciar-me se distinguem fundamentalmente das formas do outro através das quais vivencio a todos os outros sem exceção

\footnotetext{
${ }^{68} \mathrm{O}$ ser enquanto ser e sua natureza comum. A realidade da existência dos entes. A substância do ser.

${ }^{69}$ Definição dada por Da Fonseca (2012) e que a nós parece muito próxima ao que Buber e Bakhtin compartilham.

${ }^{70}$ Em Buber, do Diálogo e do Dialógico, no capítulo "O individuo na responsabilidade", página 111.
} 
O outro, o lugar do outro na obra de Bakhtin (2003), é fundamental não só para construção do "eu", mais para o autoconhecimento. Como afirma Todorov no prefácio da edição brasileira de Estética da criação verbal (2003, p.14-15), "o outro é ao mesmo tempo constitutivo do ser e fundamentalmente assimétrico em relação a ele: a pluralidade dos homens encontra seu sentido não numa multiplicação quantitativa dos "eus", mas naquilo em que cada um é o complemento necessário do outro". Essa outridade é percebida por Buber (2006) como o modo fundante da relação dialógica,

quando o homem diz $\mathrm{Eu}$, ele quer dizer um dos dois. O Eu ao qual se refere está presente quando ele diz Eu. Do mesmo modo quando ele profere Tu ou isso, o Eu de uma ou outra palavra-princípio está presente. Ser Eu, ou proferir a palavra Eu são uma só e mesma coisa. Proferir Eu ou proferir uma das palavras-princípio são uma ou a mesma coisa. Aquele que profere uma palavra-princípio penetra nela e aí permanece. (BUBER; 2006, p.43)

A questão do outro é também fundante para o estabelecimento do diálogo, o que por via de regras, vai permitir o aparecimento das relações dialógicas. Morson; Emerson (2008) afirma que, para Bakhtin (2003), o complexo de ideias que ele chama de diálogo, constitui fator de preocupação recorrente, podemos dizer que

\footnotetext{
O diálogo, para Bakhtin, é um tipo especial de interação. Infelizmente, não raro foi tomado como sinônimo de interação, ou de interação verbal em geral, e com isso se trivializou. No sentido que Bakhtin lhe conferia diálogo não pode ser equiparado a debate, nem tampouco é equivalente a "diálogo expresso composicionalmente", ou seja, a representação sequencial das vozes transcritas num romance ou numa peça. Bakhtin também nos alerta para não confundirmos o diálogo com contradição dialógica. O diálogo difere da relação Eu-tu de Buber. E muito menos se assemelha à dialética hegeliana ou marxista. (MORSON; EMERSON, 2008, p.68)
}

Sobre o pensamento de Morson; Emerson (2008) a respeito de estabelecer diferença entre o diálogo em Bakhtin(2003) e a relação Eu-Tu de Buber(1982; 2001), cabe aqui nos distanciarmos dessa conjectura. $\mathrm{O}$ fato de Buber (op. cit.) tratar o diálogo como um evento que se instaura entre o Eu-Tu não significa que esse diálogo não seja dialógico. Ao contrário, o diálogo e as outras categorias totalizadoras, como a palavra, a relação, a subjetividade, a responsabilidade o inter-humano, etc é o que vai fundamentar a existência humana é ele (o diálogo, a palavra) que se unirá com a categoria ontológica do "entre" o qual permitirá a instauração do evento inter-pessoal chamado de relação, a qual irá possibilitar o nascituro do dialogismo.

De fato, a insistência de Bakhtin (2003), em acentuar e reacentuar o sentido da palavra diálogo, por ele empregada, tem em muitos gerado certas dificuldades, justamente porque Bakhtin (op. cit.) tenta separar a palavra diálogo da ideia de interação face-a-face, de conversação. Neste caso específico, Bakhtin (2003) se ocupa não com o diálogo em si, mas com o que ocorre nele, ou nas palavras de Faraco (2009, p.61), "isto é, com o complexo de forças que nele atua e condiciona a forma e as significações do que é dito ali”. Em nosso entender, o gérmen fundamental da ideia contida na categoria 'diálogo', tanto em Buber (op. cit.) quanto em Bakthin (op. cit.), são bem próximas. A diferença surge na medida em que Buber (op. cit.) utiliza a categoria 'palavra' para pensar a vida e vivência humana em toda sua concretude e Bakhtin (op. cit.) a utiliza como fenômeno em que as relações de sentido são produzidas no material linguístico. Claro que, este ponto de vista ainda é passível de um exame mais apurado, e dada à limitação deste trabalho apenas fazemos o registro. Ainda assim, é interessante notar que, como ocorreu com Bakhtin (2003), a definição de um conceito de 'diálogo' também se tornou preocupação de Buber (1982): 
os domínios da vida dialógica e da vida monológica não coincidem com os do diálogo e do monólogo, mesmo se nestes incluirmos suas formas sem som e sem gesto. Não existem somente grandes esferas da vida dialógica que na sua aparência não são diálogo, mas existe também o diálogo que não é diálogo enquanto forma de vida, isto é, que tem a aparência de um diálogo, mas não a sua essência. Aliás, parece, às vezes, que esta última espécie é a única que ainda existe. Conheço três espécies de diálogo: o autêntico - não importa se falado ou silencioso - onde cada um dos participantes tem de fato em mente o outro ou os outros na sua presença e no seu modo de ser e a eles se volta com a intenção de estabelecer entre eles e si próprio uma reciprocidade viva; o diálogo técnico, que é movido unicamente pela necessidade de um entendimento objetivo; e o monólogo disfarçado de diálogo, onde dois ou mais homens reunidos num local, falam, cada um consigo mesmo, por caminhos tortuosos. (BUBER, 1982, p.54)

Ainda assim, como para Bakhtin(2003), Buber(1982) tem interesse particular por um tipo de diálogo, o que ele chama de diálogo autêntico, nesse sentido, é interessante retomarmos Carrara ( 2002) quando cita Buber (1982):

\footnotetext{
No diálogo autêntico, cada um dos participantes tem de fato em mente o outro ou os outros na sua presença e no seu modo de ser e a eles se volta com a intenção de estabelecer entre eles e si próprio uma reciprocidade viva. Vida monológica é a daquele que não é capaz de atualizar, de uma forma essencial, a sociedade na qual o seu destino o faz mover-se. A pessoa que vive de maneira dialógica responde ao que lhe é dito, não se deixando abandonar pela presença do outro que o confronta. Há reciprocidade nela. Esse outro é alguém com quem ele se comunica. Também o amor possui natureza dialógica, pois obriga o outro a sair-de-si-em-direção-ao outro. Amor que se fecha em si mesmo é Lúcifer. Não se pode, contudo, sair de si mesmo sem antes ter estado consigo mesmo. O indivíduo se torna pessoa através da experiência do diálogo.
}

Como podemos observar, para Buber(1982), a existência do homem está diretamente relacionada com a categoria do inter-humano a qual se fundamenta no diálogo. O diálogo, pensado por Buber (op. cit.), não diz respeito estritamente a uma conversação: a palavra deixa de ser um logos anunciador que apenas fundamenta a existência. Ele vai além da subjetividade, ela funda uma dimensão ontológica chamada de inter-humano. A palavra, nestes termos, evoca o ser como um ser existente; o homem, para Buber (1982), habita a palavra. Ela não é apenas proferida, mas instaura um modo de existir: o modo dialógico. Sendo dialógica, a palavra, habita o 'entre' e evoca a relação.

\section{Relações dialógicas em textos verbo-visuais online}

Uma vez percebido como as relações dialógicas são constitutivas da vida e das vivências do ser, vamos nos voltar para um modo de ser dessa vida humana: o digital. Bakhtin (2003), no ensaio "O problema do texto ${ }^{71 ", ~ v a i ~ c a r a c t e r i z a r ~ a s ~ r e l a c ̧ o ̃ e s ~ d i a l o ́ g i c a s ~ c o m o ~}$ relações de sentido que se estabelecem entre os enunciados. Ainda neste ensaio, Bakhtin (op. cit.) estabelece uma distinção entre os dois níveis de articulação da palavra, dizendo que o primeiro nível se relaciona ou remete ao elemento único e não reiterável da enunciação, o que ele vai chamar de "seu sentido completo". Já o segundo nível ele aloca dentro do nível da língua onde os elementos são reiteráveis e idênticos a cada momento em que é repetido, o que

${ }^{71}$ The Problem of the Text in Linguistics, Philology, and the Human Sciences: An Experiment in Philosophical Analysis. Speech Genres and Other Late Essays, publicada pela University of Texas Press. No Brasil, foi publicado pela primeira vez na coletânea intitulada Estética da criação verbal 1979. 
se constitui em um nível inferior da interpretação. Esse pensar o dialogismo é levado para os estudos dos gêneros discursivos enquanto espaços de usos da linguagem; a abertura que fazemos aqui em relação a essa constatação diz respeito ao espaço em que essa formulação surge e se distancia do campo retórico e se aproxima do campo prosaico.

Este é o núcleo conceitual a partir do qual as formulações sobre os gêneros
discursivos distanciam-se do universo teórico da teoria clássica criando um lugar
para manifestações discursivas da heteroglossia, isto é, das diversas codificações não
restritas à palavra. Graças a essa abertura conceitual é possível considerar as
formações discursivas do amplo campo da comunicação mediada, seja aquela
processada pelos meios de comunicação de massas ou das modernas mídias digitais,
sobre o qual, evidentemente, Bakhtin nada disse mas para o qual suas formulações
convergem. (MACHADO, 2012, p. 152).

No contexto de uma abordagem dialógica em ambiente online é necessário assinalar a natureza dessa esfera da atividade humana, ou seja, a natureza digital. Assim, em um contexto de produção e interação nesses ambientes é preciso considerar o espaço em que esses textos verbo-visuais e esses enunciados estão alocados, ou seja: é preciso considerar o software como um objeto histórico e linguístico através do qual os sujeitos de linguagem interagem e estabelecem relações. Como já foi verificado por Souza (2010a; 2010b) quando percebeu que na esfera digital os textos, vídeos, sons, imagens estão alocados em softwares, sendo o software o dado próprio em que o sujeito de linguagem estabelece relação com os textos e discursos em ambiente digital. Nessa direção foi verificado também que o software possui uma base hipertextual que orienta, por assim dizer, as relações estabelecidas na esfera digital.

Os principais pontos assinalados nos estudos de Souza (op. cit.) podem ser sintetizados pelo que segue: a) o software é o suporte dos textos e gêneros em ambiente digital; b) os gêneros na esfera digital possuem uma natureza hipermodal, eles são constituídos não só pelo material verbal, mas também pelo material verbo-visual. Além disso, eles possuem uma natureza hipertextual que lhe permite executar funções; c) o sujeito interage com esses textos verbo-visuais de maneira contínua estabelecendo com eles uma relação de responsividade; d) nas interfaces dos softwares estão alocados enunciados concretos de outros sujeitos. Essas observações são importantes e nos leva a pensar com Grillo (2012, p. 326) que "para mapear os fundamentos de uma abordagem bakhtiniana de enunciados verbo-visuais, quatro aspectos devem ser brevemente tratados: a epistemologia dialógica, a estética, a noção de autoria e a delimitação do objeto de estudo".

No escopo deste trabalho, vamos tomar um exemplo elementar dessa manifestação verbo-visual, trata-se de uma publicidade eletrônica enviada por e-mail (ver imagem 02). Esta publicidade está alocada em um software carregado de ícones, símbolos e menus, além dos enunciados verbo-visuais específicos da composição do gênero. É interessante notar que a representação do signo no software é de ordem metafórica, além disso, é perceptível a diferença desses elementos verbo-visuais dos encontrados em outro ambiente, como uma sala de bate-papo, por exemplo. Neste trabalho entendemos que os elementos verbo-visuais alocados em interfaces de softwares, possuam um mínimo dialógico. Sobre essa questão do dialógico presente não só nas palavras, $\operatorname{Buber}(1982$, p.40) vai ponderar que:

o dialógico não se limita ao tráfego dos homens entre si; ele é - é assim que se demonstrou para nós - um comportamento dos homens um-para-com-o-outro, que é apenas representado no seu tráfego. Assim sendo, mesmo que se possa prescindir da fala, da comunicação, há, contudo, um elemento que parece pertencer indissoluvelmente à constituição mínima do dialógico, de acordo com seu próprio sentido: a reciprocidade da ação interior 
A reciprocidade da ação interior (elemento constitutivo da essência dialógica), nos elementos verbo-visuais, foi verificada por Souza; Carvalho (2007) em artigo intitulado de "O signo no gênero e no suporte virtual" quando então alertou para o fato de que os signos nos softwares divergem gradativamente em forma, significado e função. Isso é perceptível se considerarmos os dois exemplos que apontamos anteriormente, o do e-mail e o da sala de bate-papo. É claro para qualquer sujeito que utilize esses dois ambientes que a ação real dos signos diverge gradativamente, dito de outro modo: a organização verbo-visual dos elementos presentes em uma interface de software aciona funções distintas e estão diretamente correlacionadas com a esfera de utilização desse software; o que se percebe é que a relação que o sujeito estabelece com esses elementos verbo-visuais, não sofre variação pois o sujeito que utiliza essa forma experiencia e atualiza a forma computacional. A clareira que percebemos quando nos debruçamos sobre essa questão diz respeito ao modo eu-isso de Buber (2001, p.11):

Eu não posso experienciar ou descrever a forma que vem ao meu encontro; só posso
atualizá-la. E, no entanto, eu a contemplo no brilho fulgurante do face-a-face, mais
resplandecente que toda clareza do mundo empírico, não como uma coisa no meio
de coisas inferiores ou como um produto de minha imaginação, mas como o
presente. Se for submetida ao critério da objetividade, a forma não está realmente
"aí"; entretanto, o que é mais presente do que ela? Eu estou numa autêntica relação
com ela; pois ela atua sobre mim assim como eu atuo sobre ela.

Ainda assim esses elementos verbo-visuais permitem ao sujeito estabelecer relação com o outro em toda sua concretude. Essa questão é interessante, pois se trata de uma questão fundante para o estabelecimento do diálogo e das relações dialógicas, mais ainda, é a partir da observação da dinâmica que ocorre no uso desses elementos verbo-visuais que podemos perceber melhor o que ocorre nos diálogos, nas relações dialógicas.

Como já foi observado por Souza; Carvalho (2007), frequentemente atribuímos a um signo um significado. Com as novas tecnologias, um signo além de deter um significado, detém uma função. Esse dado nos permite elevar o estudo dos elementos verbo-visuais a um novo patamar: não é mais possível atribuir a um signo um significado desprovido de uma função, este só pode ser percebido na relação que desencadeia. Essa relação pode ser uma relação mecânica como o acionar um botão ou clicar em uma imagem e ser remetido para outro ambiente ou pode desencadear também uma relação dialógica, como acontece com o envio de emoticons dentro de um bate-papo online. Aqui o dado próprio aponta para uma constatação primária: nas interações online os elementos não verbais se apoiam em um signo verbal (a palavra), conforme podemos verificar na imagem 01:

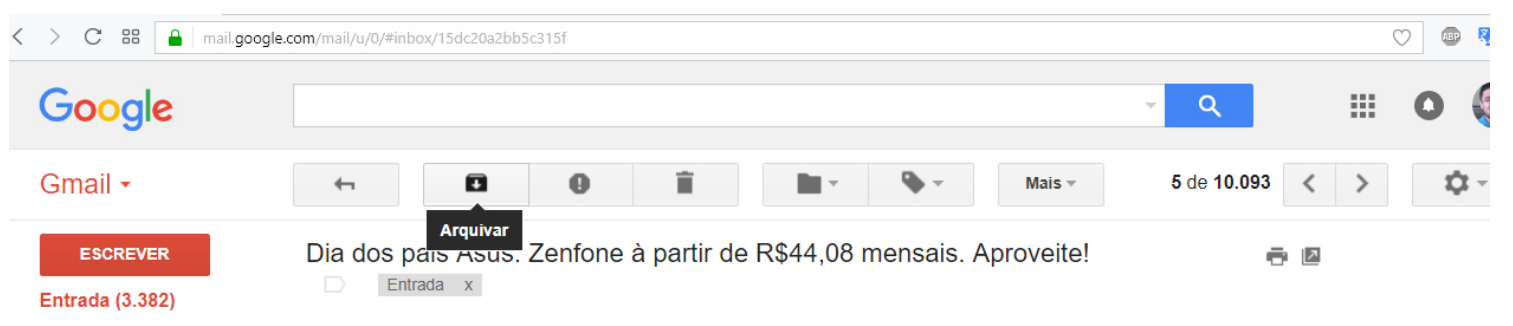

Imagem 01

$\mathrm{Na}$ imagem 01 temos um ícone que guarda em si uma função (a de arquivar a publicidade) e, além disso, quando acionado deixa vir à tona a palavra 'arquivar'. Há nesse 
caso algo próximo ao que Bakhtin $(1975)^{72}$ chamou de hibridização ${ }^{73}$. Como aponta Morson; Emerson (2008, p.357) na hibridização propriamente dita "apenas um discurso está presente de forma explícita; o outro discurso dialogizante é percebido nos seus efeitos sobre o primeiro. É visto como a linguagem do outro a partir da qual se produz a imagem da primeira linguagem, mas não é ele próprio diretamente visível".

Esse processo das relações verbo-visuais com a totalidade do gênero é percebido na relação com a interface do software, a interface, (forma visível de um software) - ver imagem 02 - é uma expressão em potencial constituída através de signos - abstração do que pode vir a ser - que em conjunto formam e dão forma ao gênero na esfera digital, como já mostrou Souza; Carvalho (2007).

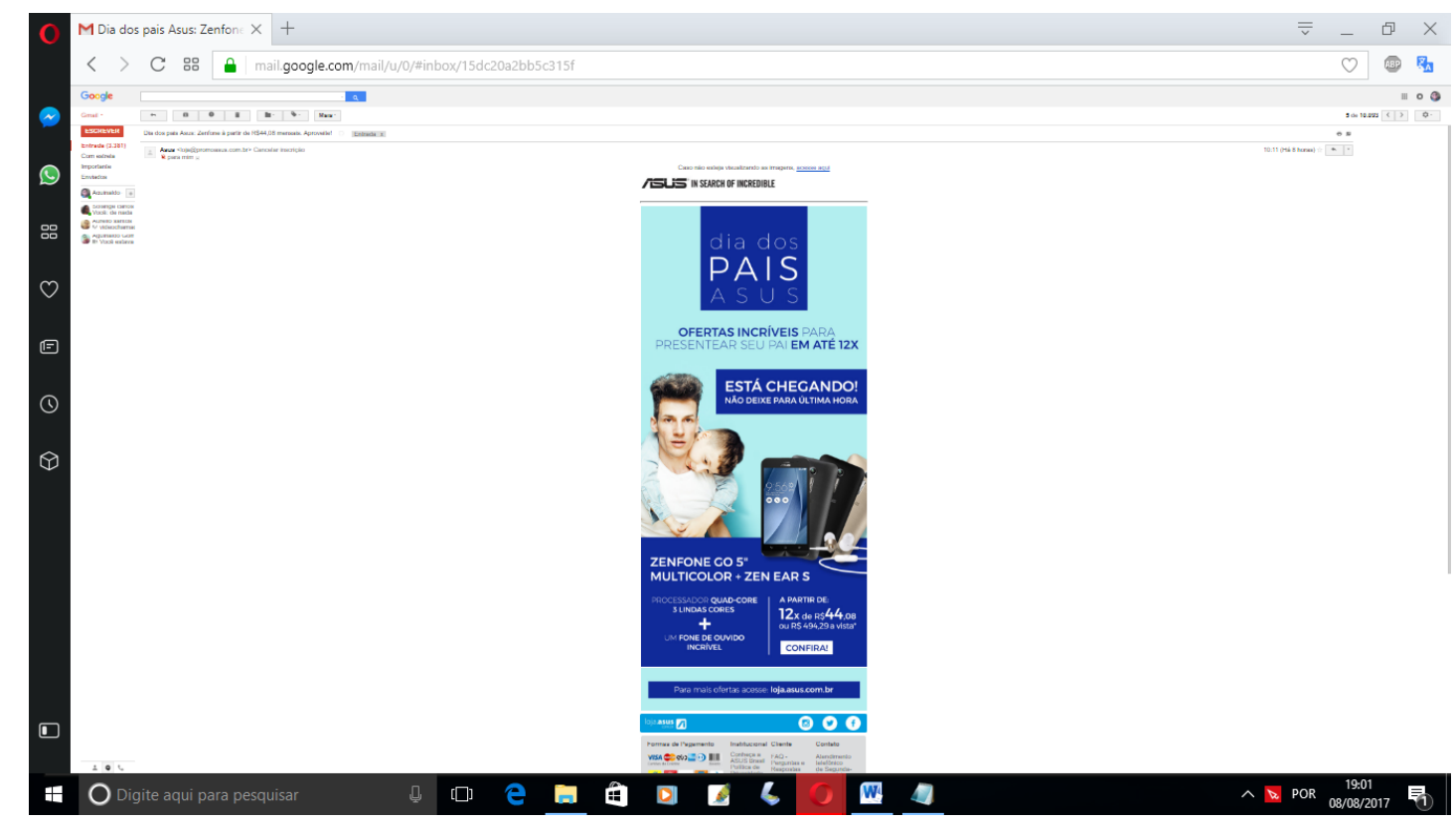

Imagem 02

A mesma hibridização, a mesma mistura de elementos verbo-visuais, é percebida em outros gêneros da esfera digital, veja por exemplo o gênero charge (imagem 03) e o gênero fórum de discussão (imagem 04). Nesse sentido, Bakhtin (1975 apud Morson; Emerson (2008, p.358), mostra que:

A hibridização não-intencional, inconsciente, é um dos modos mais importantes na vida histórica e na evolução de todas as linguagens. Podemos dizer que essa linguagem e essas linguagens mudam historicamente sobretudo por meio de tal hibridização, por meio de várias 'linguagens' coexistentes.

O processo de hibridização das formas verbo-visuais é percebido na interface ${ }^{74}$ de qualquer software, Souza (2010b, p. 119) vai ponderar que

\footnotetext{
72 Em Morson; Emerson (2008)

${ }^{73}$ Embora nos escritos de Bakhtin(2002) não exista uma correlação entre a linguagem verbo-visual e o processo de hibridização, achamos interessante aproximar essa categoria bakhtiniana do pensamento que estamos trilhando.

${ }^{74}$ A forma visível do software, o lugar onde os signos, os elementos verbo-visuais se deixam mostrar
} 
essa forma do software é também uma forma material, isto é, uma totalidade acabada que materializa e permite o uso de escolhas de formas linguísticas que resultam em posições axiológicas as quais, por sua vez, são capazes de gerar múltiplas interrelações responsivas. Essa materialidade do software permite ao usuário estabelecer relação com os hipertextos e gêneros. E é nessa forma material que nasce o aspecto dinâmico, hipertextual dos enunciados produzidos sobre um software.

A hibridização introduzida nos ambientes online é fundamental para que os sujeitos estabeleçam relações. É ao interagir com um elemento verbo-visual que eu, do meu lugar único na existência, posso estabelecer relações de sentido com o outro. O processo de hibridização perpassa os softwares (ver imagem 03 e 04) de tal maneira que a percepção que temos é que tal processo pertence à essência e se encontra na base da construção desses artefatos computacionais.

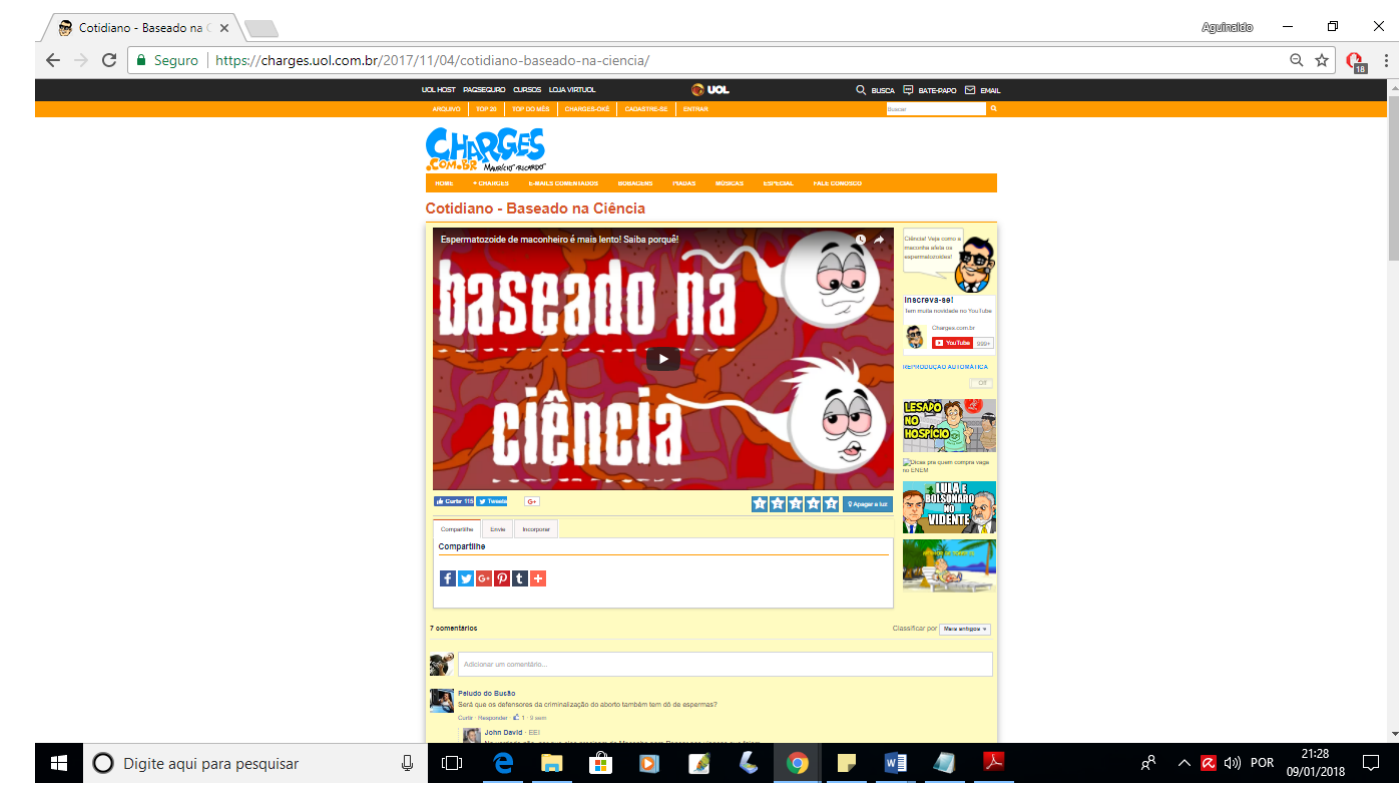

Imagem 03 (charge online)

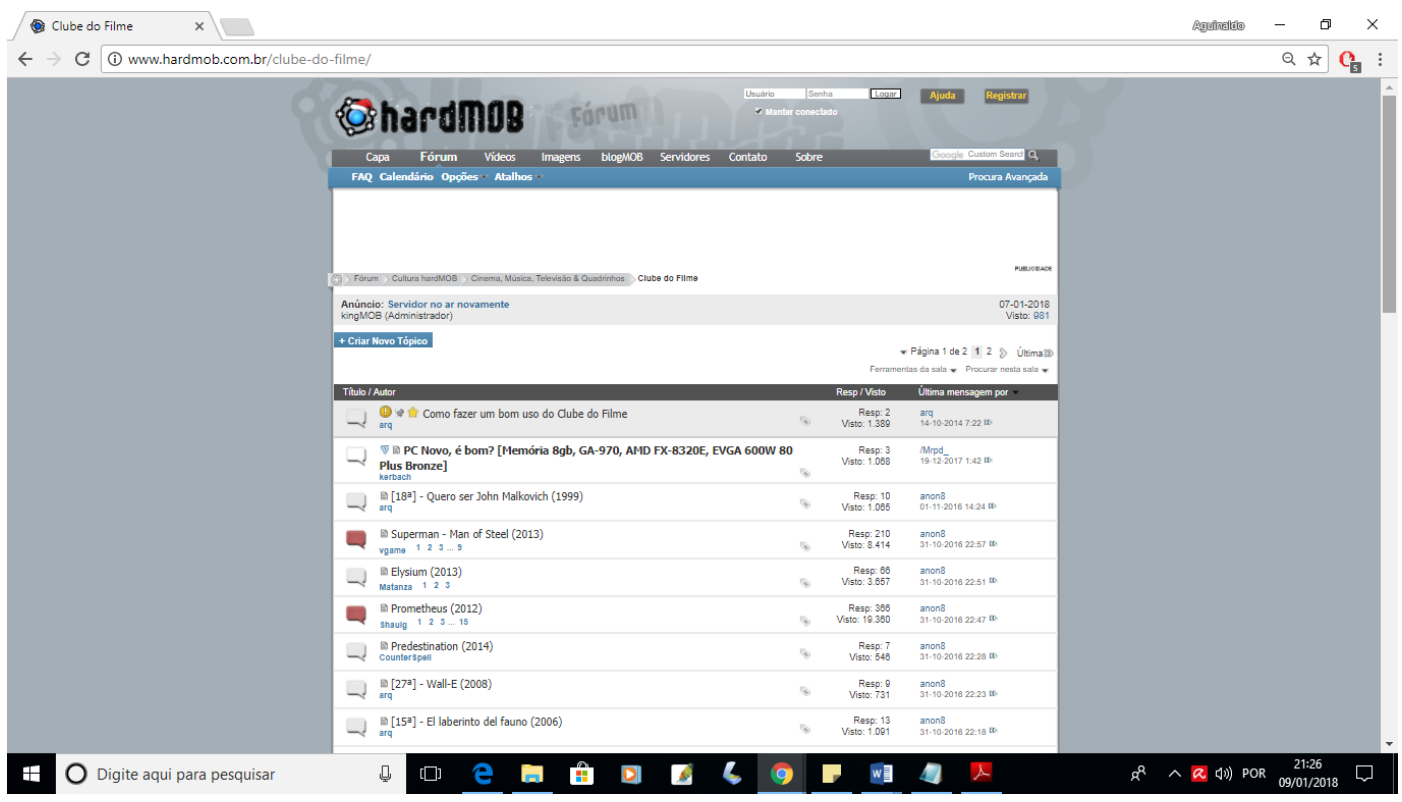

Imagem 04 (fórum de discussão) 
A palavra dialogizada e o elemento não verbal, nesses ambientes, são a ponte entre o eu e o outro. Este ponto que acabamos de assinalar exclui o caráter eminentemente monológico das formas computacionais e leva o analista para o âmbito dos enunciados concretos e das esferas de manifestação desses discursos. A esse respeito Bakhtin (2002, p.184) vai notar que as relações dialógicas são possíveis de existir "entre outros fenômenos conscientizados desde que esses estejam expressos numa matéria sígnica. Por exemplo, as relações dialógicas são possíveis entre imagens de outras artes". Essa parece ser também a posição de Buber (1982) que na página 60 do livro "Do diálogo e do dialógico" pondera que o dialogismo perpassa a arte, a música, a escultura, a arquitetura etc., para Buber (op. cit) o dialógico é o modo fenomenológico da vivência humana.

\section{Considerações finais}

Iniciamos esse trabalho investigando um conceito basilar em Bakhtin, o dialogismo. Mas se a categoria filosófica, chamada de 'o dialógico', é cara tanto para Buber (1982) quanto para Bakhtin(2003), o que torna o pensamento filosófico de Bakhtin (2003) original? Responder a essa questão não é tarefa fácil, faz-se necessário examinar outras categorias dentro do pensamento do russo. De imediato poderíamos dizer que o que dá especificidade ao pensamento bakhtiniano é o fato dele explorar o conceito de dialogismo dentro da língua/linguagem. No ensaio "O problema do texto" 75 ", Bakhtin (op.cit.) vai caracterizar as relações dialógicas como relações de sentido que se estabelecem entre os enunciados. Ainda neste ensaio, o autor estabelece uma distinção entre os dois níveis de articulação da palavra, dizendo que o primeiro nível se relaciona ou remete ao elemento único e não reiterável da enunciação, o que ele vai chamar de "seu sentido completo" e o segundo nível ele aloca dentro do nível da língua onde os elementos são reiteráveis e idênticos a cada momento em que é repetido, este se constitui em um nível inferior da interpretação.

Holquist (1993) vai indicar que essa discussão, em torno da palavra, irá abrir espaço para a noção de dialogismo, a qual foi trabalhada por Bakhtin (op. cit.) e o Círculo em obras seguintes. Nesse sentido, não soaria estranho dizermos que a proposta filosófica bakhtiniana centra-se na palavra como um fenômeno da estrutura social a qual irá ser crucial, para o pensador, trabalhar a noção de diálogo e dialogismo. Em relação a este, reiteramos Faraco (2009, p. 69) quando diz que "Bakhtin e o Círculo entendem as relações dialógicas como espaços de tensão entre enunciados. Estes, portanto, não apenas coexistem, mas se tencionam nas relações dialógicas". Não seria equívoco dizer que a concepção de diálogo e de dialogismo, em Bakhtin (2003), serviram de base, por exemplo, para os conceitos de enunciado, enunciado concreto e gêneros do discurso que foram largamente trabalhados pelo Círculo.

Desse modo, é possível dizer que embora não tenha se ocupado particularmente dos enunciados verbo-visuais não seria equivoco apontar que os fundamentos da teoria dialógica da linguagem urgem como condição de possibilidade para uma análise da linguagem que tenha por finalidade analisar as relações verbo-visuais que são tão comuns no mundo contemporâneo. Ainda assim, temos a compreensão de que em ambiente online a análise de enunciados verbo-visuais deve levar em conta também a relação que esses enunciados estabelecem nesse novo ambiente de enunciação. O modo de enunciação digital é cada vez mais sustentado por signos que ao serem acionados executam funções, essas funções são o núcleo a partir do qual a dinâmica discursiva e a alteridade constitutiva se manifestam. Isto é, se pensarmos com Bakhtin (2002, p. 184) que as relações dialógicas são possíveis não apenas

${ }^{75}$ The Problem of the Text in Linguistics, Philology, and the Human Sciences: An Experiment in Philosophical Analysis. Speech Genres and Other Late Essays, publicada pela University of Texas Press. No Brasil, foi publicado pela primeira vez na coletânea intitulada Estética da criação verbal 1979. 
entre enunciações integrais (relativamente), "mas entre qualquer parte significante do enunciado, inclusive a uma palavra isolada, caso esta não seja interpretada como palavra impessoal da língua, mas como signo da posição semântica de um outro, como representante do enunciado de um outro, ou seja, se ouvimos nela a voz do outro".

\section{REFERÊNCIAS}

BAKHTIN, Mikhail. Estética da criação verbal. São Paulo: Martins Fontes, 2003. 476p . Problemas da poética de Dostoiévski. Trad. Paulo Bezerra. 3. ed. Rio de Janeiro:

Forense Universitária, 2002. p. 327-358.

“O Problema do Texto". In: Estética da Criação Verbal. SP: Martins Fontes, 2003

. Para uma filosofia do ato responsável. Trad. aos cuidados de Valdemir Miotello e Carlos Alberto Faraco. São Carlos: Pedro \& João Editores, 2010, 160p.

. O problema do conteúdo, do material e da forma na criação literária. In: Questões e

literatura e de estética: A teoria do romance. Trad. Aurora F. Bernadini e outros. São Paulo: Hucitec, 1998, p. 13-70.

BUBER, M. Do diálogo e do dialógico. Perspectiva, 1982.

Eu e tu. (8a. ed.). São Paulo: Centauro, (2001). (Originalmente publicado em 1923)

DA FONSECA, Afonso. Metodologia gestaltificativa: O que se quer dizer quando se fala em uma metodologia gestáltica. Gestética. Gestática. Gestaltificativa. IGT na Rede, Rio de Janeiro, RJ, 9.17, 3112 2012. Disponível em:

$<$ http://www.igt.psc.br/ojs/viewarticle.php?id=391>. Acesso em: 15072017.

FARACO, Carlos Alberto. Linguagem \& Diálogo: as ideias linguísticas do círculo de Bakhtin. São Paulo, Parábola editorial, 2009.

GRILLO, S. V. C. Fundamentos bakhtinianos para a análise de enunciados verbovisuais. In:

Filologia e Linguística Portuguesa, v. 14, p. 233-244, 2012.

HOLQUIST, M. Prefácio. In: BAKHTIN, M. M. Para uma filosofia do ato. Trad. Carlos

Alberto Faraco e Cristovão Tezza (para fins didáticos), 1993.

MACHADO, Irene. Gêneros discursivos. In: Bakhtin: conceitos-chave. Beth Brait, (Org.)

5.ed. São Paulo: Contexto, 2012.

MORSON, Gary Saul; EMERSON, Caryl. Mikhail Bakhtin: criação de uma prosaística.

Tradução de Antonio de Pádua Danesi. São Paulo: Edusp, 2008.

NUTO, J. V. C.. A Influência de Martin Buber no Conceito Bakhtiniano de Dialogismo.

Revista Intercâmbio dos Congressos Internacionais de Humanidades (UnB), v. 1, p. 130139, 2008.

STRATHERN, Paul. Kierkegaard em 90 minutos: 1813-1855. Trad. Ana Marcos. Mem Martins :Inquérito, 1999.

SOUZA A.G. Como os softwares são fabricados: um olhar ergolinguístico. Revista Eutomia. Ano III Volume 1/julho 2010a.

. Software: esboço de um estudo para as ciências da linguagem. Dissertação de

Mestrado em Letras/Linguística UFPE 2010b.

SOUZA A.G; CARVALHO E.P.M. O signo: no gênero e no suporte virtual. Revista Letra Magna. Ano 04 n.07. 2007.

Recebido em 02/08/2017

Aceito em 16/12/2017 